\title{
Coulisses
}

Revue de théâtre

1 | Printemps 1990

Varia

\section{Le Satyre}

Karl-Heinz Götze

Traducteur : Gérard Jugan

\section{OpenEdition}

\section{Journals}

Édition électronique

URL : http://journals.openedition.org/coulisses/1550

DOI : 10.4000/coulisses. 1550

ISSN : 2546-9460

\section{Éditeur}

Presses universitaires de Franche-Comté

\section{Édition imprimée}

Date de publication : 1 avril 1990

Pagination : 35-37

ISSN : 1150-594X

\section{Référence électronique}

Karl-Heinz Götze, «Le Satyre », Coulisses [En ligne], 1 | Printemps 1990, mis en ligne le 04 juillet 2017, consulté le 21 octobre 2019. URL : http://journals.openedition.org/coulisses/1550 ; DOI : 10.4000/ coulisses. 1550

Ce document a été généré automatiquement le 21 octobre 2019

Coulisses 


\section{Le Satyre}

\section{Karl-Heinz Götze}

Traduction : Gérard Jugan

« Je suis le meilleur auteur dramatique vivant, il n'y a aucun doute là-dessus. N'importe quel écolier vous le dira. » C'est en ces termes que s'exprime Heiner Müller au sujet de Heiner Müller (Il faut que les poètes soient bêtes, un entretien avec l'écrivain H. Müller, in Die Zeit, $\mathrm{n}^{\circ} 34,14-8$ 1987). Quant à savoir si cela est exact, on peut en discuter. On ne sait même plus s'il parle sérieusement en le disant, car il est rare qu'il pense sérieusement tout ce qu'il raconte dans d'innombrables interviews :

Aujourd'hui je peux dire cela et demain le contraire... J'ai du mal à me prendre au sérieux. Je suis toujours plein d'admiration, à la télévision, pour les auteurs à qui l'on pose des questions sur leur œuvre et qui sont capables de dire avec le plus grand sérieux ce qu'ils ont écrit et pourquoi et pour quelle raison. Il m'est impossible, en tant que personne, de prendre au sérieux l'auteur que je suis et c'est pourquoi il m'arrive dans des interviews de dire les pires bêtises et peut-être, aussi, quelque chose d'important.

2 En tout cas, il y a une chose que l'on sait : Heiner Müller est avant Thomas Bernhard et Botho Strauss l'auteur dramatique de langue allemande le plus joué de nos jours; à l'âge de soixante ans, c'est déjà un auteur classique. Cela n'a pas toujours été ainsi. Pendant douze ans, en RDA, ses pièces n'eurent pas le droit d'être montées et à l'Ouest aussi, il fallut attendre les années soixante-dix pour qu'un large public commence à s'y intéresser. Pour les uns, Müller était suspect parce qu'il abordait les problèmes du socialisme eux-mêmes, pour les autres parce qu'il montrait ces problèmes sans leur apporter de solution, parce qu'il n'avait pas envie d'édulcorer l'image effrayante du socialisme édicté par l'Etat au moyen d'une perspective optimiste de l'Histoire.

Comme tous les auteurs dramatiques importants de son époque, Müller a été à l'école de Brecht et comme tous les auteurs dramatiques importants, il a rompu avec ses paradigmes au moment où Brecht se montre trop confiant dans la dialectique de l'Histoire :

J'ignore qui est bon et qui est mauvais et la seule chose qui me dérange, par exemple chez Brecht, c'est qu'il porte des jugements de valeur sur ses personnages. La supériorité de Shakespeare est qu'il ne porte pas, lui, de jugements de valeur. 
Chaque personnage a sa légitimité. Aucun d'eux n'est bon ou mauvais et je crois que chez moi non plus aucun personnage n'est bon ou mauvais. débuts est soumise au régime stalinien, il est menacé, lui aussi, de faire de la prison sous le nouveau régime et il passe à l'Ouest. Le fils reste. La RDA représentait à cette époque, pour les meilleurs écrivains allemands, malgré tout, un espoir.

7 Son premier succès, Müller le remporte avec Der Lohndrücker (Le Briseur de salaire). La pièce, écrite en 1956, figure à l'époque dans les manuels scolaires : elle met en scène le héros socialiste. Dans la nouvelle mise en scène que Müller lui-même en donne en 1988 et que l'on a pu voir en France également, apparaît l'autre face du héros socialiste : le nouvel état naît avec les hommes du passé, avec des arrivistes et des dénonciateurs.

8 En septembre 1961, quelques semaines après la construction du mur, un théâtre universitaire de Berlin-Est monte pour la première fois la pièce de Müller Die Umsiedlerin (L'Émigrante). Elle montre la collectivisation de l'agriculture en RDA : un combat à mort, un combat lourd de contradictions. Elle montre ce qui ne devait pas être montré. Après la Première, c'est l'interdiction, l'exclusion de l'association des écrivains. Au cours des années suivantes, les pièces du contre-révolutionnaire, de l'ennemi de l'État, sont tabous pour les scènes de RDA.

9 Par la suite, Müller écrit des pièces importantes, nées de la productivité qu'engendre un isolement durement acquis, des pièces sur le thème de l'Allemagne : Germania Tod in Berlin (Germania Mort à Berlin), Leben Gundlings Friedrich von Preussen Lessings Schlaf Traum Schrei (Vie de Gundling Frédéric de Prusse Sommeil rêve cri de Lessing). Les pièces consacrées à l'Antiquité : Prometheus (Prométhée), Philoktet (Philoctète), Ôdipuskommentar (ÆEdipecommentaire), Der Horatier (Horace) font apparaitre comment les archaïques relations de violence se prolongent dans les temps modernes, dans le socialisme. Les adaptations de Ciment de Gladkow et des Liaisons dangereuses de Laclos (Quartett) montrent la violence qui règne dans les relations entre les sexes. Mauser reprend la tradition de la pièce didactique brechtienne pour signifier du même coup qu'elle est révolue. 

années soixante-dix, à une époque où la dialectique de l'Histoire semble être arrivée au point mort, Müller est déjà un auteur de réputation mondiale. Mais à côté de cela, son regard se porte sur le Tiers Monde d'où sont ponctionnées les richesses qui rendent possibles des personnages comme celui de Hamlet.

11 La dernière grande œuvre de Müller, qui se compose de cinq parties relativement indépendantes, s'appelle Wolokolamsker Chaussée (La Chaussée de Wolokolamsk). Elle a été (superbement) montée dans son intégralité en France, pour la première fois, avec comme titre La Route des chars. Müller suit les traces des blindés depuis la bataille pour la défense de Moscou en 1941 jusqu'à leur entrée à Prague en 1968. Il montre comment le socialisme encerclé adopte, pour le vaincre, les méthodes de l'ennemi. Le socialisme remporte la victoire mais ce n'est pas le socialisme qui triomphe, c'est son propre ennemi.

Les événements récents en RDA ont apporté la preuve que la vision notoirement pessimiste que Müller a du socialisme a été largement dépassée par la réalité. Mais ce serait une erreur de croire que Müller, contrairement à la majorité de ses compatriotes, soit devenu un partisan du système de l'Allemagne de l'Ouest :

Il y a là quelque chose qui ressemble à une couverture bien chaude pour rhumatisants et qui recouvre l'Histoire. Et les autres ont froid. Mais la couverture suffit à donner aux gens le sentiment que tout va bien et que tout doit rester comme ça. C'est pourquoi il est si ennuyeux de vivre en République Fédérale. Je n'arrive pas à m'imaginer que je pourrais le faire, je m'ennuierais à mourir. Je vais vous raconter une anecdote : il y a trois ans, j'étais pour la première fois en Haute Bavière au bord du lac Chilmsee. C'était épouvantable car il n'y avait là que des cartes postales. Chaque maison était une carte postale et les Alpes elles-mêmes étaient impeccables. De temps à autre, quelques arbres morts. Ça fait plaisir de voir quelque chose de foutu. Alors on finit par ne plus s'imaginer ou désirer autre chose qu'une catastrophe.

Ça ne peut plus continuer comme ça. C'est tellement propre, tellement achevé, tellement saturé. Alors il se produit quelque chose qui ressemble à un immense besoin de violence et de catastrophe. C'est ce qui explique l'envie qui vous prend que ça soit foutu, l'envie qu'il y ait comme une éruption. Quand quelque chose est foutu, il y a peut-être une chance pour que quelque chose de neuf arrive ${ }^{2}$.

\section{NOTES}

1. Il s'agit d'unités de combat, constituées de soldats entre seize et soixante ans, dépourvus de formation militaire, créées par Hitler en 1944 pour pallier le manque de combattants.

2. Toutes les citations sont extraites d'interviews que Heiner Müller a accordées à l'auteur. 


\section{AUTEURS}

\section{KARL-HEINZ GÖTZE}

Professeur d'allemand à l'UFR de Lettres. K.-H. Götze a réalisé un film sur H. Müller, film qui sera présenté prochainement à l'UFR de Lettres, rue Mégevand. 